\title{
System Information Modelling in Practice: Analysis of Tender Documentation Quality in a Mining Mega-Project
}

\author{
P.E.D. Love ${ }^{\mathrm{a}}$, J. Zhou ${ }^{\mathrm{b} *}$, J. Matthews ${ }^{\mathrm{c}}$, M.C.P. Sing ${ }^{\mathrm{d}}$ and D. J. Edwards ${ }^{\mathrm{e}}$

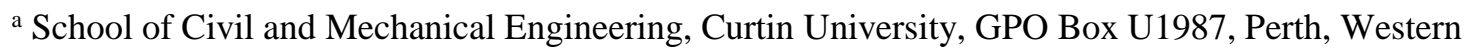 \\ Australia, Australia \\ b* Senior Research Fellow, School of Civil and Mechanical Engineering, Curtin University, GPO Box \\ U1987, Perth, Western Australia, Australia, Corresponding Author \\ c School of Built Environment, Curtin University, GPO Box U1987, Perth, Western Australia, Australia \\ ${ }^{\mathrm{d}}$ Department of Building and Real Estate, Hong Kong Polytechnic University, Hung Hom, Kowloon, \\ Hong Kong, SAR China, \\ ${ }^{\mathrm{e}}$ School of Engineering and Built Environment, Birmingham City University Centre Campus, Millennium \\ Point, Birmingham, B4 7XG United Kingdom
}

Abstract: The quality of information contained in tender documentation produced using Computer-Aided-Design (CAD) and provided in a hard-copy format to an electrical engineering contractor for a port expansion facility, which formed an integral part of an Iron Ore mega-project is analyzed. A System Information Model (SIM), which is an object oriented approach, was retrospectively constructed from the documentation provided to assist the contractor with their tender bid preparation. During the creation of the SIM, a total of 426 errors and omissions were found to be contained within the 77 tender 'drawing' documents supplied to the contractor by an Engineering, Construction, Procurement and Management (EPCM). Surprisingly, 70 drawings referenced in the tender documentation, and the Input/Output lists and Cause/Effect drawings were not provided. Yet, the electrical contractor was required by the EPCM organization to provide a lump sum bid and also guarantee the proposed schedule would be met; the financial risks were too high and as a result the contractor decided not to submit a bid. It is suggested that if the original tender documentation had been prepared using a SIM rather than CAD, the quality of information presented to the contractor would have enabled them to submit a competitive bid for the works. The research concludes that the economic performance and productivity of mining projects can be significantly improved by using a SIM to engineer and document electrical instrumentation and control (EIC) systems.

Keywords: Errors, omissions, mining, object oriented, information redundancy, SIM 


\subsection{Introduction}

43 Design and engineering is only effective when it serves its intended purpose and is constructible within desired budget, time, quality and safety objectives [1]. An electrical instrumentation and control (EIC) contractor, for example, must be supplied with high quality information so as to enable them to construct their work effectively and efficiently and without hindrance [2-7]. Rarely, however, is the design and engineering of EIC documentation for mining projects produced with all the necessary information being made available when tenders are sought [8]. More often that not contractors are supplied with incomplete, conflicting and erroneous documents [9]. In addition, contractors are often required to submit a tender within a limited time frame. In such a case, a considerable amount of contingency may be incorporated into the bid, especially if requests for information (RFI) fail to provide information needed to ensure works can be carried out efficiently and effectively. Consequently, bids can be inflated and/or render a project unfeasible.

In this paper, the quality of information in the tender documentation provided to an electrical engineering contractor for a port expansion facility (which formed an integral part of an Iron Ore mega-project) is analyzed. Notably, such information is rarely made available for analyses due to its commercial sensitivity. Moreover, there has been limited empirical research that has examined the quality of information contained in the documentation that has been prepared to solicit tenders. Such research, however, is needed to demonstrate the prevailing issues that adversely impact the costs of mining projects to clients.

The participating contractor is hereafter referred to as 'Contractor A' to preserve confidentiality agreements made between both parties. The aim of this paper is to examine the nature of errors, omissions and information redundancy that were presented in the tender documents and the potential risk exposure that the contractor would have faced in the field should they have been awarded the project. To address the deficiencies contained within the drawings provided in tender documents for EIC systems, it is suggested that the use of an object oriented approach, referred to as a System Information Model (SIM), to design and document the project instead of Computer-Aided Design (CAD) can significantly reduce the occurrence of errors, omissions and information redundancy [2-6]. Thus, a SIM can be integrated with a Building Information Model (BIM), yet the use of software applications of this nature to produce EIC object models are rarely used in the Australian mining sector [6]. Yet in the mining industry, EIC accounts 
for approximately $29 \%$ of the world's capital expenditure on plant. Furthermore, in plant operations, EIC typically accounts for $60 \%$ of maintainable items as well as being critical to safe and efficient operations [6]. Despite their importance, there has been limited research that have examined EIC systems within an object oriented environment within the construction, energy and resources sectors [5,10]. A SIM forms an integral part of the BIM nomenclature and has been described in detail in Zhou et al. [7].

\subsection{Case Study}

Thus, against this contextual backdrop, the following research question is examined in this paper using a case study: Is a SIM able to provide significant cost and productivity improvements during the production of design and engineering documentation for EIC systems? To address the aforementioned question, triangulation was used as the basis for data collection process, which took place at the offices of an electrical engineering firm who had been invited to tender for a system upgrade for an existing Port Facility.

Triangulation involves the use of multiple research methods and/or measures of a phenomenon, in order to overcome problems of bias and validity [11,12]. Data collection methods employed were unstructured interviews, observations and documentary sources (e.g., tender documents). In addition to the active day-to-day interactions between the participating organization and lead researcher, unstructured interviews with key personnel were also undertaken by a secondary researcher. This approach was undertaken to provide additional context to the problem and provide validity to the research process.

\subsection{Background}

Growing demand for iron ore from countries such as China and India has stimulated the development of existing facilities to better accommodate increased iron ore production from 45 Million tons per annum (Mtpa) to 155Mtpa. The expansion project (referred to as T155), situated in Western Australia (WA), required additional port facilities and rail systems. Company Iron Ore (IO) procured the project using an Engineering, Procurement, Construction and Management contract (EPCM). In this instance, the EPCM contractor assumes responsibility for coordinating all design, procurement and construction work. 
107 The expansion project consisted of two parts: (1) the facility upgrade at the existing port; and

108 (2) the construction of a rail spur to the two new mine sites. The railway spur was 109 approximately $135 \mathrm{~km}$ long connecting the mainline railway to the newly developed mine sites

110 which include an airstrip, operations and construction accommodation, plant, roads, power,

111 water, fuel, utilities and stockyards. An upgrade to the existing mainline railway was also

112 undertaken to enhance the rail system's capacity. A $155 \mathrm{~km}$ duplication of the selected section

113 of the mainline rail was also constructed to connect the port and an existing mine site.

115 The port facility's upgrade was planned to be completed within three stages. Stage one, referred

116 to as T60, constructed a second outloading circuit, which increased the port's export capacity

117 from 45Mtpa to 60Mtpa. The works that had been completed were dredging, installation of a

118 new wharf for the third berth, a shiploader, sample station, reclaimer, two transfer stations and

119 all the conveyors between them. Stage two provided the port with the second and third 120 inloading circuits. The work involved the installation of two new train unloaders, a stacker, 121 three transfer stations, the conveyors between them and the associated equipment. Stage three involved an additional outloading circuit, which increased the port's export capacity further to 155Mtpa. The work involved the construction of a new wharf for the fourth and fifth berths, a shiploader, reclaimer, sample station and all the interconnecting conveyors and Transfer

125 Stations.

\subsection{Control System Upgrade for Port Facilities}

128 The control system expansion of the port facilities were also implemented in three stages in accordance with the project schedule. In Stage one (Upgrade to 60Mtpa) ten new High Voltage

130 (HV) and Variable Speed Drive (VSD) switch rooms were constructed and linked into the

131 existing T45 network. Stages two and three consisted of constructing $21 \mathrm{HV}$ and VSD switch

132 rooms which were tied back into stage one's T60 network.

134 The tender documentation that described the control system upgrade requirements of the 135 existing port facilities were provided to several Electrical Engineering firms for review prior 136 to bidding for the works. The tender invitation was sent to potential contractors on 12/04/11.

137 The tender submission deadline was 03/05/11, which meant that interested applicants needed 138 to complete the activities identified within three weeks. A lump sum bid was required for the 139 control system by 'Company IO' and all work specified in the contract was required to be 
140 completed by the specified date. In addition, it was explicitly stated that any cost overrun 141 incurred by latent uncertainties and insufficient information contained within the contract 142 documents were at the contractor's risk.

\subsection{Tender Documentation}

145 The tender documents comprised of 126 files, containing a total of 1687 pages. The tender 146 documents studied in this research described the requirements of the control system 147 installation, Programmable Logic Controller (PLC) and Supervisory, Control and Data 148 Acquisition (SCADA) software development of the port facilities. Figure 1 illustrates the 149 structure of the proposed control system after the expansion project. In addition to the existing 150 system, the port facility expansion project requires new field devices, marshalling panels, 151 switch rooms and the cables to be installed on site. The newly introduced devices were required

152 to seamlessly interact with the existing system forming an integrated monitoring and control 153 system, which would provide information for the plant operation managers' supervision. In 154 preparing the tender, an electrical contractor would typically undertake the following steps:

156 - allocate a dedicated engineering team to undertake the tender;

157 - read through the 126 files (1687 pages) provided as part of the tender package;

158 - determine the system functions and requirements to be achieved;

159 - examine the 77 contract drawings and estimate the quality of the required equipment to $160 \quad$ construct the control system;

161 identify errors and omissions contained in the contract drawings;

162 raise an RFI to the principal's engineering team seeking clarifications of the problems 163 identified;

164 investigate the principal and technical specifications and determine the proper classes of 165 the equipment and cables required by their corresponding safety classifications;

166 estimate the Input/Output(I/O) points of the expansion system;

167 - investigate the existing T45 system to determine the interface and control schemes 168 between the proposed and existing systems;

169 - clarify the functions to be coded so as to realize the required control system 170 functionalities;

171 - define the Human Machine Interface (HMI) graphics;

172 - estimate and calculate the cost of equipment, cables and software; 
- determine the manpower requirements;

- $\quad$ complete all the tables and schedules listed in the tender package (over 30); and

- $\quad$ submit the tender application.

A detailed examination of the tender documents by the contractor and researchers revealed numerous errors, omissions, and misleading and conflicting information. Consequently, the date required to produce a tender was considered unachievable by the electrical contractor. In particular, designing and constructing the project's first switch room within seven weeks would have been a herculean task considering the paucity and inaccuracy of information provided. 'Contractor A' decided not to risk submitting a tender due to the gravity of commercial risks posed. In trying to decipher and comprehend the scope and nature of work contained within the tender package, a principle engineer stated:

$$
\begin{aligned}
& \text { 'The documents contained many internal conflicts and omissions so we failed to } \\
& \text { understand the required scope. The work required was not sufficiently defined for a } \\
& \text { lump sum contract. Offering a bid, in its present form, would be an unacceptable } \\
& \text { commercial risk to us.' }
\end{aligned}
$$

The overall structure of the control system, as defined in the tender documentation, was not clearly specified. The typical process within ports for exporting iron ore consists of unloading (from trains or trucks), transporting and sampling and loading (to ships). Often (depending on the size and capacity of port), a number of devices and facilities are involved such as train unloaders, conveyors, shuttles, stackers, reclaimers, sample stations, ship loaders and other miscellaneous equipment. To achieve a safe and environmental friendly production process, all the devices were required to conform to a robust safety control system where a number of risk controls must be implemented (i.e. dust suppression, structural anti-collision, materials route sequencing and stockpile management). Several environmental auxiliary systems, such as oil water separation, sewerage treatment and potable water generation, also needed to be integrated into the plant to facilitate production. All the systems are controlled by the PLCs and supervised via the Central Control Room (CCR) through Supervisory Control and Data Acquisition (SCADA) networks. It was implied that the process and safety control system would be designed together to maximize productivity by being capable of immediate fault detection and diagnosis so as to minimize system down time. 
207 A brief overview of the existing control system for the transportation of iron ore was presented 208 in the tender documents and included information such as the number of control rooms 209 installed, the configuration of the SCADA system and its functionalities. It also numerated the 210 new devices to be installed so as to form the $2^{\text {nd }} / 3^{\text {rd }}$ inloading and outloading circuits. However, 211 tender documents failed to provide a clear hierarchy of how the control devices (new and old)

212 should be integrated together to form a Distributed Control System (DCS). The contractor's 213 principle engineer, suggested that a preferred DCS structure would have assisted them to 214 understand the design and should have contain the following key features:

- hierarchies of the control network such as divisions within the central control unit, local control unit, communications, power supplies and field devices;

- $\quad$ divisions of the process control system and the safety control system;

- types of field buses jointing the control network and the connection techniques interfacing different types of buses; and

- configuration of Supervisory Control and Data Acquisition (SCADA) networking; and

- devices involved in each hierarchy.

Moreover, the tender documents did not specify how the expansion project could be integrated into the existing system. For example, a portion of iron ore from the new train unloaders (TU602, TU603) were to be shunted to an existing stacker (SK701) through a new transfer station (TS906) and an existing stacker conveyor (CV911) for stockpile distribution. This raised the question as to how TS906 and CV911 would react at the failure of stacker SK701 (Figure 2). As the new inloading and outloading circuits would work in conjunction with the existing circuits, PLC coding needed to effectively integrate both new and old systems. In the absence of a clear description of the system integration, applicants were unable to accurately estimate the coding workload involved.

\subsection{Research Findings}

A total of 77 EIC drawings were provided in the tender package. These drawings included 60 single line diagrams (SLD) to illustrate how various configurations of the HV, VSD and motor control panels were to be constructed, and eight Piping and Instrumentation Diagrams (P\&IDs) describing the process flows and installed instruments. 
240 The relationships between the cables and components were extracted from the tender 241 documentation and inputted into a SIM. This enabled a description of the connected systems 242 such as control, power, information technology (IT) and communications using a single digital 243 representation [2]. The tender documents, however, did not include a cable schedule and as a 244 result, designs had to be manually transferred from CAD drawings into a SIM; this established 245 a 1:1 relationship between designs to be constructed in the real world and their digital 246 realizations. Each piece of equipment was created with 'Type' (i.e. defined equipment 247 functionalities) and 'Location' (i.e. described the physical position of equipment) attributes. 248 Such classifications, enabled engineers to browse the SIM model and locate the required 249 information. For example, a conveyor drive motor (CV915-EM01) can be found under the 250 folder 'TypelMotor' as well as the folder 'LocationlCV915'. As each cable or component is 251 only modeled once, errors and omissions contained within the CAD drawings were identified and rectified during the SIM conversion process.

\subsection{Errors and Omissions}

The completed modelling process identified a total of 1545 cables and 1518 components within the 77 drawings. Numerous errors and omissions found would have hindered the engineers' ability to interpret the information contained within these tender documents. These errors and omissions were classified as follows:

260 1. Incorrect labeling: Cables or components are labeled with incorrect names;

$2612 . \quad$ Inconsistent labeling: Cables or components are named differently within various contractual drawings;

263 3. Incorrect connection: Cables or components were connected to wrong connections;

264 4. Drawing omission: Cables and components were missing from some drawings;

265 5. Missing label: Cables or components are drawn on drawings but are not labeled;

266 6. Incomplete labeling: Labels of cables or components are not completely shown.

268 A thorough review of the tender documents was conducted to identify the extent of errors and omissions found (Table 1). It can be seen that a total of 426 errors and omissions occurred within the 77 drawings. A total of 84 omissions (65 cables, 19 components) were identified on the CAD drawings; as information was not dynamically linked, information traceability was 
significantly reduced. A total of 244 errors and omissions (i.e. 57.28\% of all problems

273

274

275

276

277

278

279

280

281

282

283

284

285

286

287

288

289

290

291

292

293

294

295

296

297

298

299

300

301

302

303

304 identified) were attributed to cables. $182(42.72 \%)$ errors and omission were associated with components. Noteworthy, the classification of 'Missing Label' was the most prevalent accounting for 59.86\% of all issues identified. A typical example of 'Missing Label' is denoted in Figure 3 (a portion of drawing 515P-10016-DR-EL-3203) where cables and components were created but corresponding labels not allocated.

\subsection{Reference Drawing Numbers}

Considerable amounts of cross coupled reference drawing numbers were identified in the drawings. Notably, 70 of the drawings referred to were not made available to the applicants at the tender package and three drawings were mistakenly referenced. For example, Figure 4 (a portion of drawing 505P-10016-DR-EL-0505) illustrates that a transformer TF586 and motor control center MC586 are shown in drawing 505P-10016-DR-EL-0507. However, they could not be located in the designated target drawing.

A total of 203 reference drawing labels that appeared on 77 contract drawings were not annotated completely. For example, a reference drawing was labeled as 505P-10016-DR-EL$x \times x \times$ where the last four digits were replaced by ' $x \times x \times$ ' instead of a specified drawing number. Given such an obscure expression, it proved impossible to locate the drawing where the reference information resides.

\subsection{Unavailable Cable Schedule}

In the case of electrical engineering projects, there is a proclivity for cable schedules to be used to document inter-connections between components and cables, and to estimate the quantity of materials used to form the control networks. If the information extracted from cable schedules is different from that expressed on a drawing, then the risk of an error or omission arising is elevated. No cable schedule however was provided in the tender documents and so consequently, contractors tendering for the project could not check that the information conveyed on the drawings with the cable schedule. Furthermore, to take-off the quantities, the contractors would have had to examine all the drawings, which would have been an unproductive process.

\subsection{Information Discrepancy}


305 A list containing the instrumentations required was provided to the tenderer for reference 306 (Table 2). Major discrepancies were found between the EPCM organization's estimations and

307 what were actually required. Table 2 reveals that the numbers of instruments calculated from 308 the available 77 drawings are far less than those estimated by the EPCM. It was also observed 309 that many instruments found on the drawings are not mentioned by the EPCM. Table 3 310 identifies several examples of instrumentations that were missing from the EPCM's 311 estimations but were identified on drawings. Such information discrepancies would have 312 prevented engineers from accurately determining the required equipment and man-hours to 313 complete the project.

315 To demonstrate the information discrepancies inherent within the tender documents, the control 316 systems of three equivalent conveyors (CV908, CV914 and CV916) were chosen and 317 compared. By examining the Control and Operating Technical Specification (COTS) 318 documents provided in the tender package, the basic functionalities and the associated equipment that consisted of the control system of a typical iron ore conveyor were determined

320 (Table 4). The first column in Table 4 specifies the basic functionalities for each conveyor and the second column lists the devices required to perform key functionalities. The numbers of equipment involved may vary due to different lengths and locations of the conveyor systems. Designs of the three conveyors were analyzed and the devices associated to each conveyor system were extracted from the 77 tender drawings (Table 4). It was apparent that a large number of devices were missing from the designs of conveyors CV908 and CV916. Only a few devices could be identified, for example, motors and the associated equipment, which are used to drive the conveyor belts.

Safety control devices, which are used to stop a conveyor system in case of any hazardous events, were also not provided. Though more information was provided for conveyor CV914, omissions could still be identified and included gearboxes and associated devices between motors and belt pulleys that had been omitted from the drawings. Moreover, belt weighers (which calculate the weight of ore on conveyor belts), and hand switches (used to manually operate the belt winch) could not be found in the designs of CV914, CV908 or CV916. 
It was also found that an I/O list, which is used to define the inputs and outputs of the system, was not issued with the tender documentation. An I/O list provides a tool to measure the project complexity and estimate the man-hours to complete the work. As the I/O list was not made available, the contractor could not calculate the numbers of ports for the field instruments and control devices. Cause/Effect $(\mathrm{C} / \mathrm{E})$ drawings, which are used to document the functions of a control system (i.e. descriptions of what actions will be taken in the presence of a cause event), were also not provided to the tenderers. Consequently, the contractor was unable to estimate the number of PLCs and remote I/O modules to be used and the labor required to code the control system.

\subsection{Information Redundancy}

350 Information redundancy embedded within CAD drawings has been identified as another critical element that contributed to delays experienced during the engineering phase [2]. Each equipment item in the real world may appear several times on different drawings forming a 1:n mapping. The redundant information for cables and components identified from the tender drawings are presented in Table 5. In total, 1348 cables and 1334 components appeared once on those 77 drawings; 196 cables and 144 components appeared twice; 22 components appeared three times; and 12 components appeared four times. Surprisingly, one component appeared nine times! In this instance, a change to any object acts as a catalyst for manually changing drawings, which is a costly and time-consuming process.

360 Prior to the production of engineering documentation, a draftsperson is required to determine the exact information that should be presented and the correct relationships between components for each particular drawing. A draftsperson also ensures that labels for cables and components remain consistent with one another to avoid confusion or any misunderstanding. It is estimated that 3020 person-hours were required to produce the 77 tender drawings, and an average of 39.22 person-hours per drawing. The market pay rate for a draftsperson in WA at the time of the tender was being prepared was AU\$130 per hour; this work approximately amounted to AU $\$ 392,600$ in direct pay and possibly more if indirect costs were included.

369 For the port expansion project a total of 8633 drawings were used to document the electrical 370 engineering related designs including: 831 layout diagrams; 398 general arrangement diagrams; 168 single line diagrams: 2767 schematic diagrams: 1644 termination diagrams; and 
2825 other miscellaneous drawings. Assuming the drawings were of a similar quality to the tender drawings, then a total of $338,586.26$ person-hours would be required to create the 8633 drawings at a cost of AU $\$ 44,016,213$. The original budget for the port expansion project was AU $\$ 2.4$ billion with $12 \%$ of the budget allocated to the EPCM, which is approximately AU\$288 million. The electrical engineering related design and documentation required 20\% of the EPCM cost (AU\$57.6 million). Thus, the cost to produce the 8633 electrical drawings consumed $76.42 \%$ of the electrical engineering portion of the budget and $1.83 \%$ of the entire project's budget. Notably, this is only for the draftsperson's cost to generate the initial drawings. The cost of revising these drawings due to errors and omissions has not been considered.

Analysis of the 77 drawings revealed that $56(72.73 \%)$ contained errors or omissions and a total of 115 RFIs would have been raised to address these problems. In addition, it is estimated that on average, each one of the 56 drawings would have been revised twice after the RFI process; though discussions with the contractor suggested that this was a conservative estimate. As a result, it is estimated that a total of 6446 out of the 8633 drawings would be revised twice. All the revised drawings and their previous versions would need to be archived for version control purposes. The total number of drawings to be controlled would be 21,555. To deal with these drawings more efficiently, a sophisticated numbering system is required; where drawings are categorized and numbered according to their various types and functions. Multiple copies of these drawings can then be printed and issued to different contractors.

Three weeks were insufficient for the contractor to prepare a lump sum bid due to the onerous nature of the documentation provided. The errors, omissions and conflicts contained within the tender documents would have hindered the contractor's ability to interpret the design correctly and present a competitive bid. Decisions taken (based on the erroneous information) could have potentially lead to rework being undertaken downstream and potentially jeopardize the entire project's success.

\subsection{System Information Model}

To effectively and efficiently address the problems that were identified in this case study, it is suggested that an object oriented modelling process enabled using a SIM should be employed in EIC projects rather than using a documentation process that utilizes CAD. A SIM can be 
applied to model the connected systems where components are interconnected and possess various relationships. For example, when a SIM is used to model the electrical, power and communication systems, the physical objects and cables can be modelled as digital components and connectors in a database, which can be accessed through specific software such as Dynamic Asset Data.

The SIM forms a digital representation of a 'real system' and each physical object only needs to be modeled once. Therefore, a 1:1 relationship is established between the real world and the model [2,7]. The data stored in a SIM is dynamically linked and therefore enable efficient management of the information [5]. Engineers can work collaboratively and concurrently on the same project model by creating the components and relationships among them [2]. Thus, duplicated modeling of an identical device can be detected and avoided automatically [5]. As each object modeled is allocated with a unique tag number, the problem of 'missing labels' is eliminated $[6,7]$.

Object attributes, (such as type and specification) can be created and assigned to each individual component and connector [5]. These attributes and the associated functions enable the model to be used during the entire lifecycle of a project [3]. A SIM model can be accessed either through a database hosted on a local computer or though remote cloud based services. The devices used to access the database can be a desktop computer, laptop, industrial tablet or smart phone.

On completion of the design, the model is protected from any unauthorized changes to the data stored. As a result, the design can then be exported and issued to other users as a read-only copy that is made available via a 'Kernel' (Figure 5). Users can access the design information based on their authorization level. Private user data can be created and attached to the model such as attributes, photos and documents. To protect the design from unauthorized changes, the contents of the Kernel can only be modified by the design engineers. If users identify conflicts or design errors in the Kernel, an RFI can be generated from a dedicated folder within the user portal. A spreadsheet can be automatically generated that contains all the object information either in Microsoft Excel or portable document format (pdf.) file format [7]. On receipt of the spreadsheet, the project team can review the design and rectify the problems before generating and exporting a new 'revised' Kernel to users for further application [7]. 
With the adoption of a SIM, drawings can be eliminated and the error rectification process

440 becomes straightforward, as all required changes can be carried out within the digital model.

441 This approach eliminates the need for an engineer to identify all other relevant drawings and

442 thus revise them manually. Time and cost can be therefore reduced and productivity increased

443 [2]. When CAD drawings are used, relationships between components contained within

444 various drawings are denoted by reference numbers that increase the propensity for errors to

445 be made. The linkages between components can become very complex if a project's size

446 increases. Incorrect or incomplete labeling reduces information traceability. As noted above,

447 the allocated time to recover this missing data can significantly be increased. The use of SIM

448 overcomes this issue. For example, in Figure 6 an engineer can inspect the connection of a

449 junction box (JB-101) directly within a SIM model. The components connected to the selected

450 junction box can be displayed automatically and dynamically, and as a result the tracing of

451 connections via drawing reference numbers is no longer required.

453 Quantity take-offs can be accurate when using a SIM. Interpreting and recovering information 454 presented on several drawings is clearly an unproductive process; errors and omissions contained within drawings can adversely impact a contractor's procurement process (e.g. material waste, and rework). As all the components are categorized according to their 'Type' and 'Location' classes (Figure 7), users are able to identify and locate the required equipment.

458 Using the 'Quick Spreadsheet' function provided equipment numbers can be identified directly by users. Cost information for these items can also be acquired automatically through the 'cost

460 attribute', which is assigned to each individual component. This can enable users to produce an estimate and determine the man-hours required to complete the job at hand [7].

462

463 The culmination of research presented here suggests that if a SIM model had been adopted, the

464 T155 port expansion project could have been designed and progressed more efficiently as less 465 errors and omissions would have occurred. Essentially, a SIM based design can assist tenderers 466 to evaluate and prepare a competitive bid for scheduled works. A reliable and reasonable bid 467 can reduce 'risk' to the contractor but also facilitate the progress of downstream activities 468 through informed decision-making and therefore mitigate against project delays and cost 469 overruns.

$470 \quad 5.0$ Conclusion 
471 A detailed analysis of omissions, errors and information redundancy was undertaken for the

472 EIC tender for upgrading a control system. An analysis of 77 drawings provided in tender 473 documentation revealed 426 errors, and 70 drawings that were referenced had been omitted.

474 Yet, the 'Contractor A' was bound by a fixed lump sum price and a rigid project schedule.

475 Several contractors had been approached to provide a tender price by an EPCM organization.

476 However, 'Contractor A' decided not to submit a bid as the risks of financial loss outweighed

477 the opportunity to generate a profit. However, several firms did provide a tender price and the 478 contract was subsequently awarded.

479

480 Considering the quality of documentation provided, the potential for opportunistic behavior by contractors significantly increases as they accommodate for errors and omissions by submitting an increased tender price. This natural reaction is understandable considering the risk and uncertainty they are confronted with, but the creation of such opportunism provides the foundation for an adversarial environment. The rationale for EPCM organization providing contractors with such poor-quality documentation was unclear as the researchers could not gain access to those who had prepared the documentation, but it was suggested that there was a requirement by the client to be producing Iron Ore by a fixed date.

In addressing the issue of information errors, omissions and redundancy contained within the EIC documentation, the use of a SIM has been propagated and described. A SIM is a generic term used to describe the process of modeling complex systems using appropriate software such as Dynamic Asset Data. When a SIM is applied to design a connected system, all physical equipment and the associated connections to be constructed can be modeled into a database. Each object is modeled once. Thus, a 1:1 relationship is achieved between the SIM and the real world. As a result, information redundancy contained within traditional CAD documents is eliminated. Productivity is subsequently improved and the economic performance of mining projects significantly augmented when a SIM is used to engineer and document EIC systems.

It should be acknowledged, however, that the use of a SIM will not reduce errors per se; they may merely be relocated, changed or can even be hidden. The use of a SIM provides practitioners within the EIC domain with new capabilities and abilities to acquire significant increases in productivity, but it also brings new complexities too, which include:

- an increase in operational demands as projects will be expected to be completed and commissioned earlier; 
- an increased need for interoperability, coordination and integration with other disciplines that are using object-oriented software and the establishment of a consolidated point of truth; and

- a requirement for people to obtain more knowledge and skills.

510 Future research is required to address and alleviate the complexities that may materialize within

511 the introduction of a SIM. New technologies are often used by organizations to re-assert their 512 professional status, which can be seen as threatening and even result in power shifts happening.

513 A key challenge, therefore will be to educate EIC practitioners about the benefits of using a

514 SIM rather than CAD and develop new processes and procedures that can accommodate its

515 implementation throughout the mining sector.

Acknowledgements: The authors would like to thank the four anonymous reviewers and the Editor-in-Chief Professor Skibniewski and Associate Editor Professor Castro-Lacouture for their constructive and insightful comments, which have helped us improve the quality of this manuscript.

\section{References}

524 [1] McGeorge, J.F., Design productivity: a quality problem, ASCE Journal of Management

[2] Love, P.E.D., Zhou, J. Sing, C.P and Kim, J.T., Documentation errors in instrumentation

[4] Love, P.E.D., Zhou, J., Matthews, J. and Edwards, D.J., Moving beyond CAD to an and electrical Systems: Toward productivity improvement using System Information Modelling, Automation in Construction. 35 (2013) 448-459, https://doi.org/10.1016/j.autcon.2013.05.028.

[3] Love, P.E.D., Zhou, J., Matthews, J. and Luo, H., System information modelling: enabling digital asset management. Advances in Engineering Software. 102 (2016a) 155165, http://dx.doi.org/10.1016\%2Fj.advengsoft.2016.10.007.

538 [5] Love, P.E.D, Zhou, J. Matthews, J. and Luo, H., Object oriented modelling: retrospective 
systems information modelling for constructability assessment. Automation in Construction. 71 (2016c) 359-371, https://doi.org/10.1016/j.autcon.2016.08.032.

[6] Love, P.E.D., Zhou, J., Matthews, J. and Sing, C.P., Retrospective future proofing of a cooper mine: Quantification of errors and omissions in 'As-Built' documentation'. Journal of Loss Prevention in the Process Industries. 43 (2016d) 414-423, https://doi.org/10.1016/j.jlp.2016.06.011.

[7] Zhou, J., Love, P.E.D., Matthews, J., Carey, B. and Sing, C-P., Object Oriented Model for Life Cycle Management of Electrical Instrumentation Control Projects. Automation in Construction. 49 (2015) 142-151, https://doi.org/10.1016/j.autcon.2014.10.008.

[8] Rowlinson, S. (1999), A definition of procurement systems. Procurement Systems: A Guide to Best Practice in Construction, S. Rowlinson and P. McDermott, eds., E \& F Spon, London, 27-53, ISBN: 9780415300636.

[9] Tilley, P.A., Mohamed, S., and Wyatt, A., Indicators of design and documentation efficiency. S.N. Tucker (Ed) Proceedings of the 5th Annual of International Group for Lean Construction, Gold Coast, Australia, 16th -17th July, 1997, 137-148, http://www.iglc.net/Papers/Details/31.

[10] Hanna, A.S. Boodai, F., and M. El Asmar, M., State of practice of building information 556

[11] Black, T.R., Evaluating Social Science Research: An Introduction. Sage Publications, modelling in mechanical and electrical construction industries, ASCE Journal of Construction Engineering and Management. $139 \quad$ (2013) 04013009,

[12] Denzin, N.K, The Research Act: A Theoretical Introduction to Sociological Methods, Third Edition, Prentice-Hall, Englewood Cliffs, 1988, ISBN: 9780202362489. 
Table 1. Classification of errors and omissions

\begin{tabular}{|c|c|c|c|c|c|c|c|c|}
\hline & \multicolumn{8}{|c|}{ Error Types } \\
\hline & $\begin{array}{l}\text { Incorrect } \\
\text { Labeling }\end{array}$ & $\begin{array}{l}\text { Inconsistent } \\
\text { Labeling }\end{array}$ & $\begin{array}{c}\text { Incorrect } \\
\text { Connection }\end{array}$ & $\begin{array}{l}\text { Drawing } \\
\text { Omission }\end{array}$ & $\begin{array}{c}\text { Missing } \\
\text { Label }\end{array}$ & $\begin{array}{l}\text { Incomplete } \\
\text { Labeling }\end{array}$ & Sum & Percentage \\
\hline Cable & 22 & 13 & 4 & 65 & 139 & 1 & 244 & $57.28 \%$ \\
\hline Component & 16 & 25 & 4 & 19 & 116 & 2 & 182 & $42.72 \%$ \\
\hline Sum & 38 & 38 & 8 & 84 & 255 & 3 & 426 & $100.00 \%$ \\
\hline Percentage & $8.92 \%$ & $8.92 \%$ & $1.88 \%$ & $19.72 \%$ & $59.86 \%$ & $0.70 \%$ & $100.00 \%$ & \\
\hline
\end{tabular}

574

575

576

577

578

579

580

581

582

583

584

585

586

587

588

589

590

591

592

593

594

595

596

597

598

599

600

601 
Table 2. Comparison between estimation and calculation of instrument numbers

603

\begin{tabular}{|l|c|c|}
\hline \multicolumn{1}{|c|}{ Instrument Type } & $\begin{array}{c}\text { Estimated by } \\
\text { Client }\end{array}$ & $\begin{array}{c}\text { Counted on } \\
\text { Drawings }\end{array}$ \\
\hline Belt Drift Switch & 135 & 77 \\
\hline Absolute Encoder & 6 & 3 \\
\hline Flow Switch & 16 & 13 \\
\hline Level Switch & 13 & 12 \\
\hline Magnet & 6 & 1 \\
\hline Metal Detector & 6 & 2 \\
\hline Moisture Analyser & 6 & 1 \\
\hline Pressure Switch & 184 & 8 \\
\hline Pressure Transmitter & 4 & 1 \\
\hline Proximity & 209 & 55 \\
\hline Pullwire switch & 200 & 127 \\
\hline Rip Detector & 46 & 25 \\
\hline Solenoid Valve & 209 & 39 \\
\hline Hydraulic Controller & 2 & 2 \\
\hline Temperature Switch & 3 & 0 \\
\hline Temperature Transmitter & 60 & 40 \\
\hline Tilt Switch & 28 & 0 \\
\hline Vibration Switch & 17 & 0 \\
\hline Warning Siren & 100 & 50 \\
\hline Weightometer & 20 & 8 \\
\hline
\end{tabular}

604

605

606

607

608

609

610

611

612

613

614

615

616

617

618

619

620

621 
Table 3. Instruments missing from client estimations

\begin{tabular}{|l|c|}
\hline \multicolumn{1}{|c|}{ Instrument Type } & $\begin{array}{c}\text { Counted on } \\
\text { Drawings }\end{array}$ \\
\hline Blocked Chute Switch & 28 \\
\hline Emergency Stop & 38 \\
\hline Flow Transmitter & 10 \\
\hline Hand Switch & 22 \\
\hline Isolator & 70 \\
\hline Local Control Station & 19 \\
\hline Motor & 50 \\
\hline Speed Switch & 23 \\
\hline
\end{tabular}

623 
Table 4. Comparisons between conveyors

\begin{tabular}{|c|c|c|c|c|}
\hline \multirow{2}{*}{ Functionalities } & \multirow{2}{*}{ Equipment Required } & \multicolumn{3}{|c|}{ Equipment Identified } \\
\hline & & CV908 & CV914 & CV916 \\
\hline \multirow{5}{*}{ Conveyor Operation } & Motors & 0 & 4 & 0 \\
\hline & Gearboxes & 0 & 0 & 0 \\
\hline & Hydraulic Braking System & 1 & 2 & 4 \\
\hline & Take-up Winch & 0 & 1 & 1 \\
\hline & Scraper Belt Washing & 0 & 1 & 0 \\
\hline \multirow{3}{*}{ Route Sequencing } & Speed Switches & 0 & 2 & 0 \\
\hline & Belt Weigher & 0 & 0 & 0 \\
\hline & Ore Detector & 0 & 0 & 0 \\
\hline Belt Washing & Solenoid Valve & 0 & 1 & 0 \\
\hline \multirow{6}{*}{ Motor Operation } & Motor RTDs & 0 & 12 & 0 \\
\hline & Motor Heater & 0 & 4 & 0 \\
\hline & Motor Brake & 0 & 4 & 0 \\
\hline & Gearbox RTDs & 0 & 0 & 0 \\
\hline & Master VSD & 0 & 1 & 0 \\
\hline & Slave VSD & 0 & 3 & 0 \\
\hline \multirow{3}{*}{ Brake Operation } & DOL Motor & 1 & 2 & 4 \\
\hline & Solenoid Valve & 0 & 2 & 0 \\
\hline & Pressure Transducer & 0 & 2 & 0 \\
\hline \multirow{3}{*}{ Winch Operation } & DOL Motor & 1 & 1 & 1 \\
\hline & Hand Switch & 0 & 0 & 0 \\
\hline & Position Switch & 0 & 4 & 0 \\
\hline \multirow{6}{*}{ Safety Control } & Pull Wire Switch & 0 & 34 & 0 \\
\hline & Belt Drift Switch & 0 & 10 & 0 \\
\hline & Belt Rip Detector & 0 & 8 & 0 \\
\hline & Blocked Chute Switch & 0 & 6 & 0 \\
\hline & Emergency Stop & 0 & 4 & 0 \\
\hline & Warning Siren & 0 & 10 & 0 \\
\hline
\end{tabular}


Table 5. Information redundancy

\begin{tabular}{|c|c|c|c|c|c|c|c|c|c|}
\hline Number of occurrences & $\mathbf{1}$ & $\mathbf{2}$ & $\mathbf{3}$ & $\mathbf{4}$ & $\mathbf{5}$ & $\mathbf{6}$ & $\mathbf{7}$ & $\mathbf{8}$ & $\mathbf{9}$ \\
\hline Number of cable & 1348 & 196 & 1 & 0 & 0 & 0 & 0 & 0 & 0 \\
\hline Number of component & 1334 & 144 & 22 & 12 & 4 & 0 & 1 & 0 & 1 \\
\hline
\end{tabular}




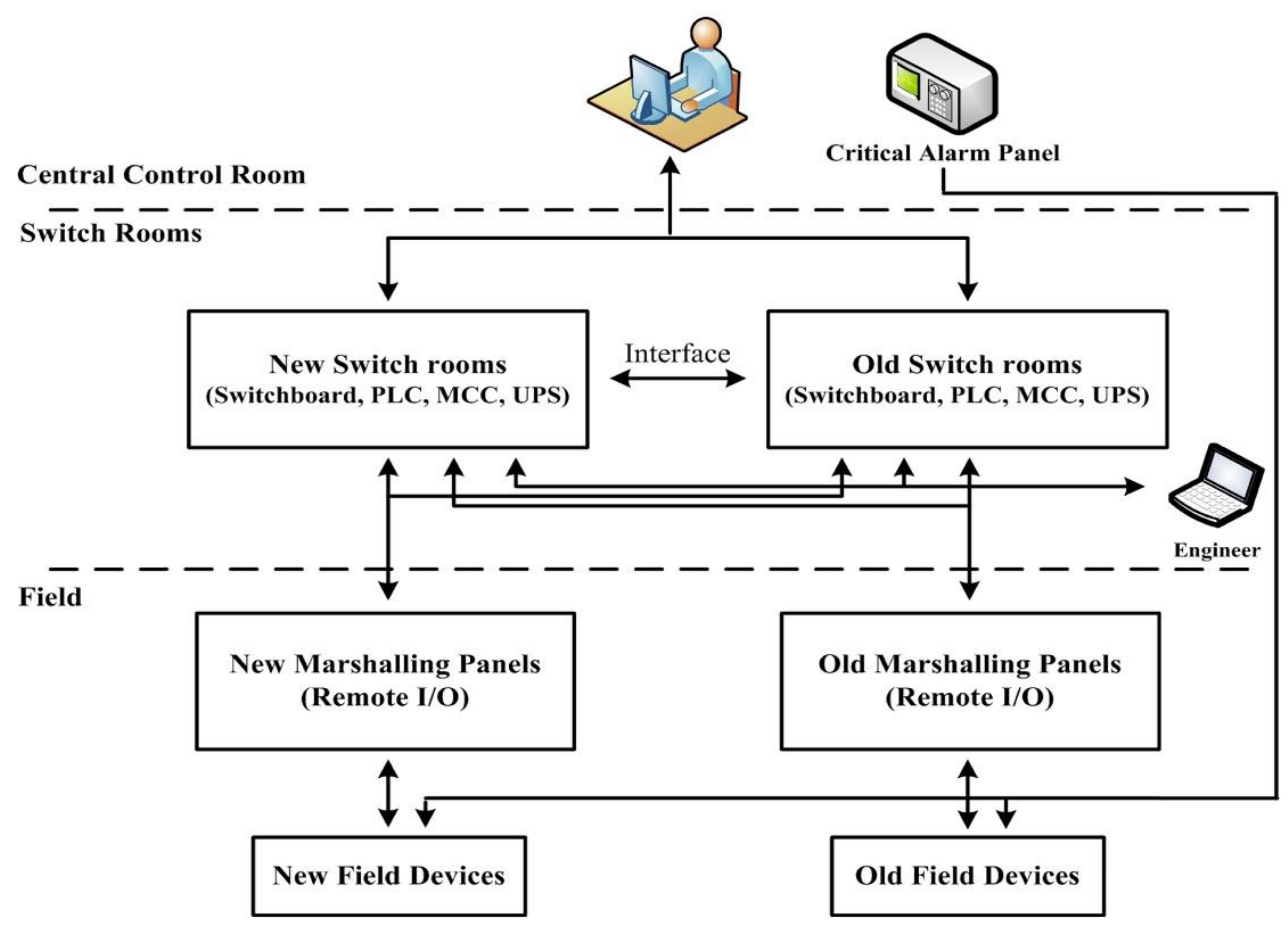

Figure 1. Control system illustration 


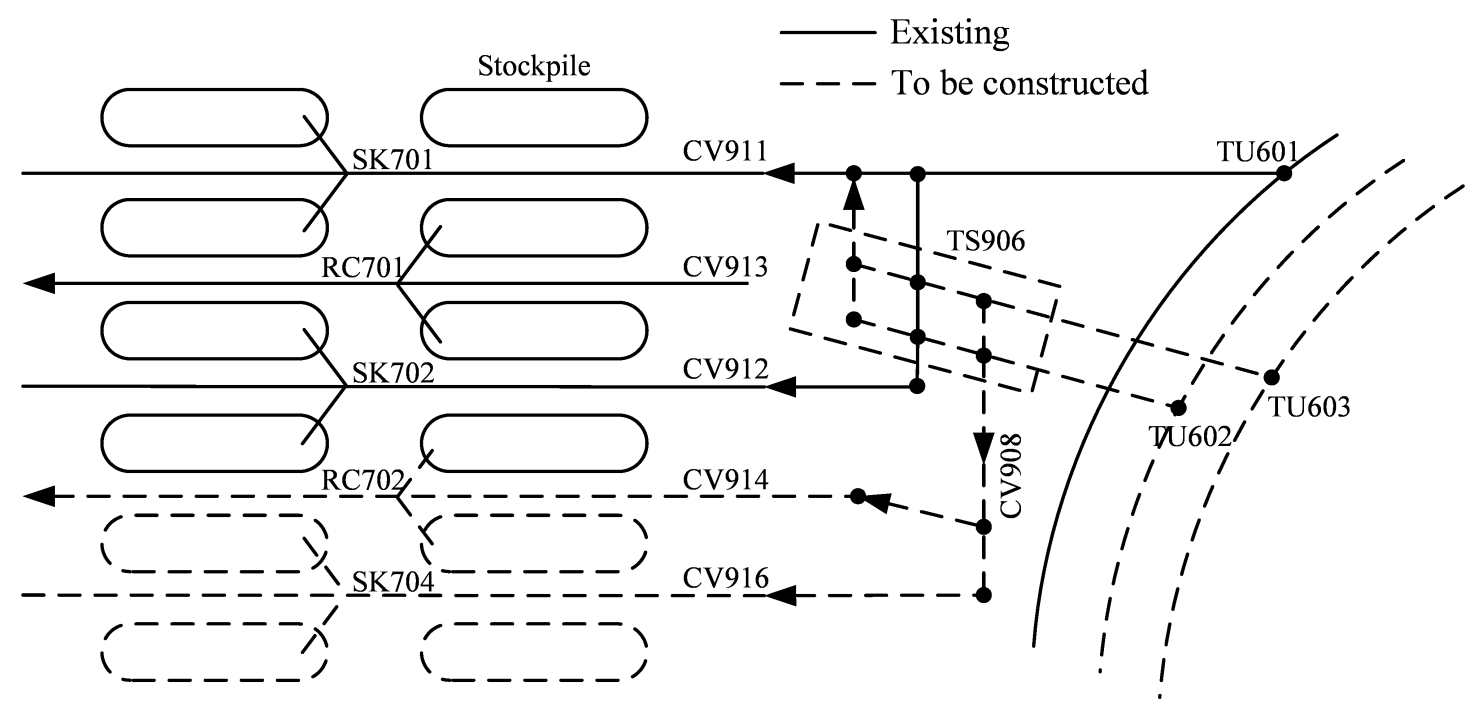

Figure 2. Connection example between circuits 


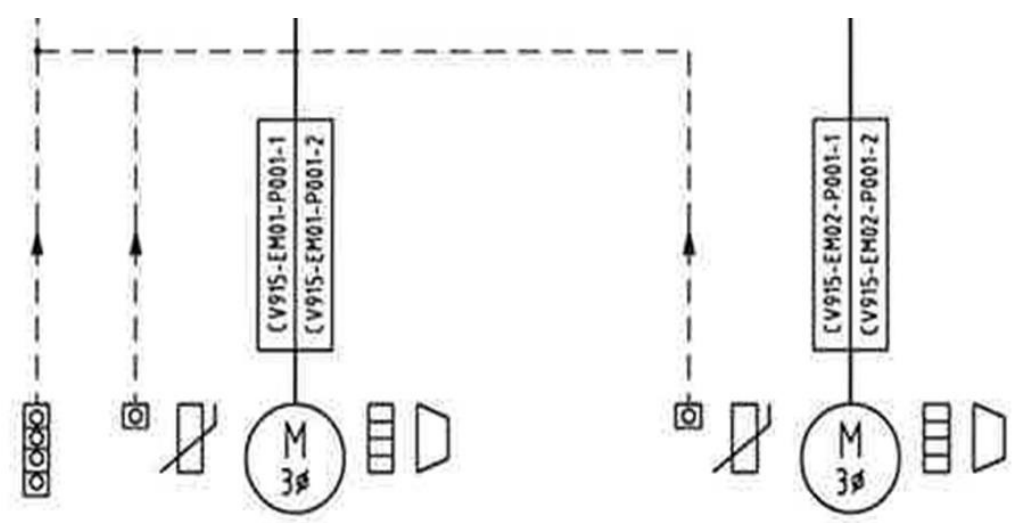

Figure 3. Example of missing label 

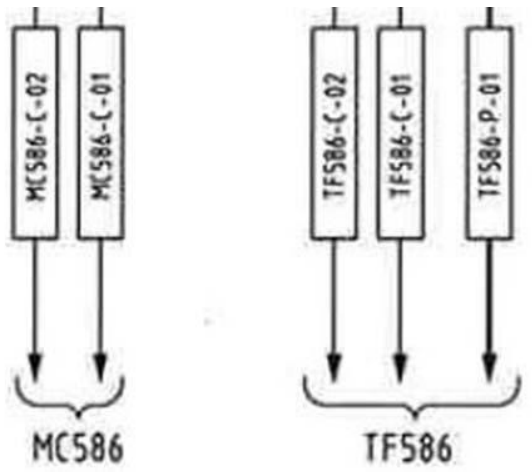

TF586 22kV/400V

MCC MC586

REF DRGS

505P-10016-DR-EL-0507

Figure 4. Example of incorrect reference 


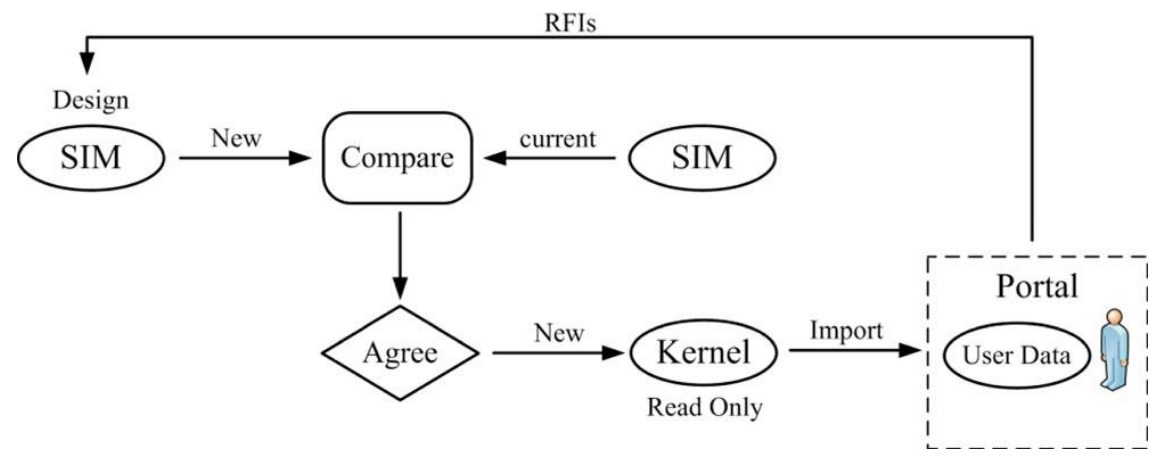

Figure 5. Kernel revision process (Adapted from Love et al. 2013) 


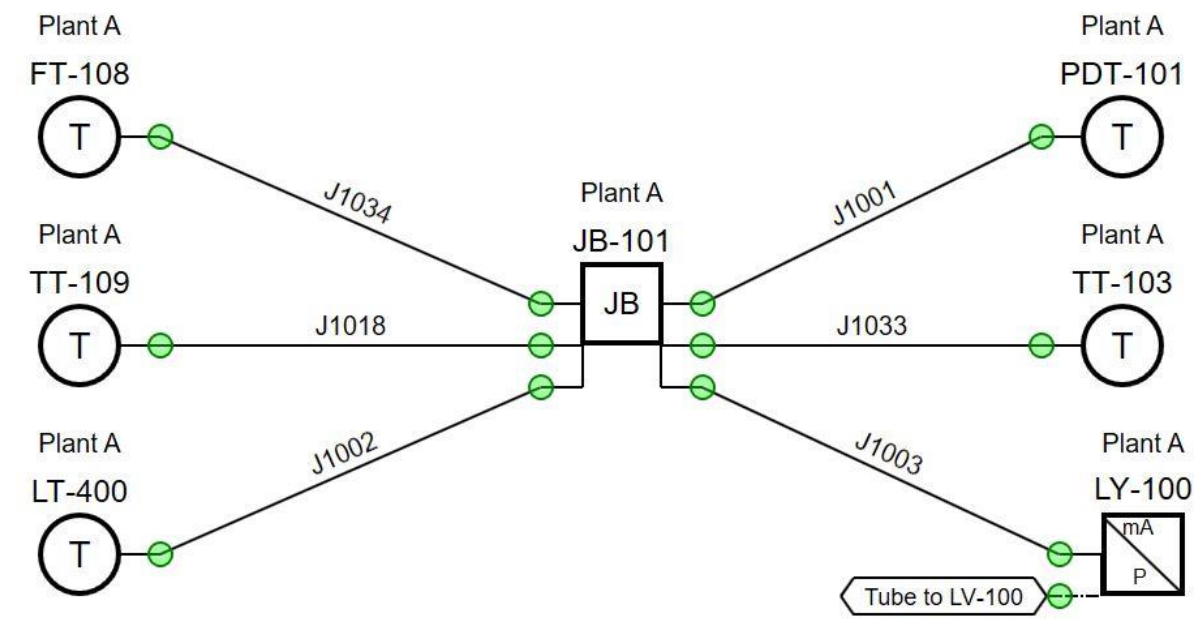

Figure 6. Example of interconnected components 


\begin{tabular}{|c|c|c|c|c|c|}
\hline Type & Location & & Type & Location & \\
\hline$\triangleright 0$ & Air Conditioner & 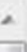 & $\triangle \bullet$ & Conveyor & a \\
\hline$\triangleright \square$ & Belt Drift Switch & & D & $\square$ CV905 & \\
\hline$\triangleright 0$ & Belt Rip Detector Switch & & $D$ & CV906 & \\
\hline$\triangleright \square$ & Belt Weigher & & $D$ & CV908 & \\
\hline$\triangleright \square$ & Blocked Chute Switch & & D & CV914 & \\
\hline$\triangleright \square$ & Decontactor Plug & & D & CV915 & \\
\hline$\triangleright \bullet$ & Distribution Board & & D & CV916 & \\
\hline$\triangleright \square$ & Dust Slurry Mixer & $=$ & D & CV917 & \\
\hline$\triangleright \square$ & E/STOP & & D & CV921 & \\
\hline$\triangleright \square$ & Encoder & & D & $\square$ CV922 & \\
\hline
\end{tabular}

Figure 7. Component classifications 